\title{
Exploring the learning curve for minimally invasive sutureless aortic valve replacement
}

\author{
Michele Murzi, MD, PhD, Alfredo Giuseppe Cerillo, MD, Danyar Gilmanov, MD, Giovanni Concistrè, MD,
} Pierandrea Farneti, MD, Mattia Glauber, MD, and Marco Solinas, MD

\section{ABSTRACT}

Objective: The study objective was to assess the learning process and quality of care of right minithoracotomy aortic valve replacement with a sutureless bioprosthesis at a single institution.

Methods: We performed an analysis of the first 300 consecutive patients (aged $76 \pm 6$ years; logistic European System for Cardiac Operative Risk Evaluation $9 \pm 6$ ) who underwent sutureless valve implantation via a right minithoracotomy by 6 surgeons at the G. Pasquinucci Heart Hospital between 2011 and 2015. The learning curve was analyzed by dividing the study population into tertiles of 100 patients each. Departmental and individual learning curves were calculated using sequential probability cumulative sum failure analysis. Quality indicators were 2 composite end points reflecting the technical success and 30-day complications.

Results: The overall mortality was $0.7 \%$ (2 patients). No significant differences were noted in terms of mortality and complications between tertiles. The sutureless valve was implanted successfully in $99 \%$ of patients $(298 / 300)$. Cumulative sum analysis failed to identify any significant learning effects for technical success. Nevertheless, surgeons A, B, and C had a small initial learning curve, and surgeons D, E, and F did not, reflecting a trend toward a positive effect of cumulative institutional experience on the individual learning curve. The 30-day complications analysis revealed a cluster of failures at the beginning of the experience. This cluster prompted an internal audit and modification of the patients' selection process. Consecutively, the procedure returned in control.

Conclusions: Right minithoracotomy sutureless valve implantation can be performed safely without learning curve effects. Cumulative sum analysis is a valuable tool to describe and monitor the learning process. The analysis can identify periods of less than expected performance and alert the team to react. (J Thorac Cardiovasc Surg 2016;152:1537-46)

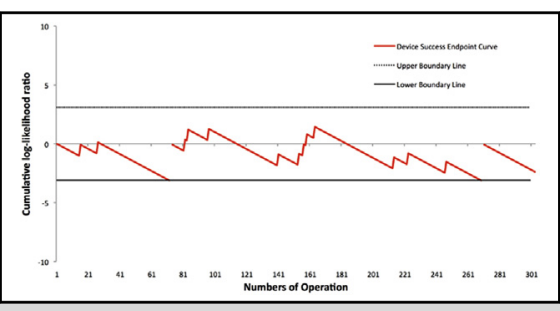

Overall institutional CUSUM curve for device success end point

\section{Central Message}

Right minithoracotomy sutureless AVR provides excellent outcomes. The learning curve can be mitigated quickly with experience.

\section{Perspective}

Right minithoracotomy AVR with a sutureless valve provides excellent short-term outcomes with low mortality and perioperative morbidity. No significant learning curve is associated with the procedure, and optimal results have been obtained since the beginning of the experience. With adequate training and supervision, the procedure can be taught to all the surgical staff.

See Editorial Commentary page 1547.

See Editorial page 1477.
Minimally invasive aortic valve replacement (MIAVR) has been increasingly accepted in the surgical community as a potential alternative to conventional sternotomy. Potential advantages of MIAVR arise from the concept that patient morbidity and potential mortality can be reduced without compromising the excellent results of the conventional procedure and include improved cosmetic results, less postoperative bleeding, fewer blood transfusions, lower intensive care unit and in-hospital stays, and the absence of sternal wound infection. ${ }^{1,2}$ On the other hand, the limited visibility and the difficulties of managing deviations from the normal course of intervention usually results in longer cardiopulmonary bypass (CPB) and crossclamping times compared with standard sternotomy aortic valve replacement (AVR).

\footnotetext{
From the Fondazione Toscana Gabriele Monasterio, G. Pasquinucci Heart Hospital, Massa, Italy.

Received for publication Sept 29, 2015; revisions received March 29, 2016; accepted for publication April 28, 2016; available ahead of print June 2, 2016.

Address for reprints: Michele Murzi, MD, PhD, G. Pasquinucci Heart Hospital Via Aurelia Sud, 100, 54100 Massa, Italy (E-mail: michele.murzi@ ftgm.it). $0022-5223 / \$ 36.00$

Copyright (c) 2016 by The American Association for Thoracic Surgery http://dx.doi.org/10.1016/j.jtcvs.2016.04.094
}

Scanning this $\mathrm{QR}$ code will take you to supplemental figure for this article.

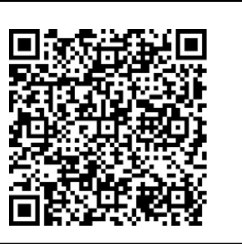




\section{Abbreviations and Acronyms \\ AVR = aortic valve replacement \\ $\mathrm{CPB}=$ cardiopulmonary bypass \\ CUSUM $=$ cumulative sum analysis \\ MIAVR $=$ minimally invasive aortic valve replacement \\ RAMT = right anterior minithoracotomy \\ TAVI = transcatheter aortic valve implantation}

The recently introduced Perceval S sutureless aortic valve bioprosthesis (Sorin Biomedica Cardio Srl, Saluggia, Italy) represents a new valve design that aims to maintain the native anatomy of the aortic root, aortic sinuses, and sinotubular junction. Similar to other sutureless bioprosthetic valves, the Perceval $\mathrm{S}$ is a self-expanding valve (only short exposition under a balloon inflation may be needed) and has the potential to shorten the implantation time, thus facilitating minimally invasive AVR. ${ }^{4-6}$ In 2010, we initiated our own series of Perceval S AVR at the G. Pasquinucci Heart Hospital, and in April 2011, we started to systematically implant the Perceval $S$ via a right anterior minithoracotomy (RAMT) (Figure E1). Before embarking on our clinical experience, we decided to assess our learning curve and monitor the surgical performance prospectively using a time series analysis. Among these, we have used cumulative sum analysis (CUSUM), which is a visual method that allows the user to easily establish whether a production process is "in control" or has become "out of control."7 The graphical presentation of CUSUM results permits rapid assessment of competence and readily demonstrates the acquisition of skill at a given task simply by assessing the slope of the curve. In the present study, we report our experience with control charts to monitor individual surgeons and departmental performance of the Perceval S RAMT performed at the G. Pasquinucci Heart Hospital over a 4-year period by 6 surgeons.

\section{MATERIALS AND METHODS \\ Patient Selection and Data Collection}

All the data presented in the study were prospectively collected and entered into our institutional database, which includes 10 sections that are filled in consecutively by anesthetists, surgeons, perfusionists, and intensive care unit and ward doctors. We analyzed data from 300 consecutive patients with severe aortic stenosis who underwent isolated AVR with the Perceval S sutureless bioprosthesis via a RAMT between April 2011 and April 2015. No cases were excluded from analysis. The 300 operations were performed by 6 surgeons (level of experience ranging from 22 to 130 operations) who gained their first clinical experience with this method at our center. Each of the 6 surgeons had at least 3 years of independent clinical operating experience with at least 100 previous aortic valve operations performed via sternotomy. The number of operations performed by each surgeon was 123 (surgeon A), 44 (surgeon B), 42 (surgeon C), 37 (surgeon D), 32 (surgeon E), and 22 (surgeon D). At the time of the study, surgeon A had extensive experience in RAMT with a sutured valve. Surgeons B and C had little experience with RAMT ( $<30$ cases). The other surgeons had no experience with RAMT and began to perform the procedure with sutureless technology. A learning curve analysis was possible because the cardiac surgery unit was under the same leadership throughout the entire study period, and methods of patient selection, operative technique, and postoperative care were based on institutional protocols that have not changed markedly over time. The study was approved by the clinical audit committee of the G. Pasquinucci Heart Hospital to meet ethical and legal requirements, and individual consent was waived.

\section{Patient Selection and Surgical Technique}

It is the policy at G. Pasquinucci Heart Hospital to use a RAMT approach for AVR whenever possible. The criteria for its application have been described by Glauber and colleagues. ${ }^{3}$ The Perceval $\mathrm{S}$ is a sutureless device designed for AVR, comprising a functional component of 2 superimposed layers of pericardium and mounted in a superelastic alloy metallic cage. The cage is collapsed before implantation and then released in the aortic root. The Perceval S sutureless bioprosthesis currently is available in 4 sizes: small, medium, large, and extra-large (covering annulus diameters ranging from 19-21 mm, 21-23 mm, 23-25 mm, and 25-27 mm, respectively). Our surgical technique for RAMT has been described. ${ }^{3}$ Briefly, it consists of a small right thoracotomy in the second intercostal space. $\mathrm{CPB}$ is established through direct ascending aorta cannulation and percutaneous femoral vein cannulation. Myocardial arrest is obtained with antegrade warm blood cardioplegia after transthoracic aortic crossclamping. The implantation technique of the Perceval $\mathrm{S}$ bioprosthesis included several steps and has been described. ${ }^{8}$ After release of the prosthesis from the holder, the guiding 4-0 polypropylene sutures are removed. The operation is completed with the closure of the transverse aortotomy. Intracardiac air is aspirated through catheters in the aortic root and left ventricle, guided by transesophageal echocardiogram. Transesophageal echocardiography is performed during the procedure to evaluate the preimplantation measurements and the prosthetic function.

\section{Data Analysis and Cumulative Sum Analysis Chartings}

The learning process was assessed in 2 steps: First the overall institutional experience was divided into tertiles according to procedure order in an effort to evaluate the influence of growing departmental surgical experience. Second, institutional and individual learning curves were generated using the sequential probability CUSUM failure analysis, which has been described in detail. ${ }^{9,10}$ A first step toward evaluating the learning curve and quality of care in surgical procedures is to select what is considered a failure and what is considered a success. Perioperative death reflects only a part of a procedural failure; therefore, it is unsuitable for monitoring the performance and learning curve. Thus, we sought more sensitive outcomes, and in advance of any analyses we decided to prospectively evaluate a device success end point, which is a technical composite end point meant to characterize the acute device and procedural factors that underlie the surgical procedure, delivery, and performance of the Perceval $\mathrm{S}$ prosthesis and a combined safety end point at 30 days, which is a composite of the most relevant patient-oriented safety end points.

The device success end point was defined as the absence of 1 or more of the following events: (1) intraoperative valve dysfunction with the need to remove and reimplant the Perceval S valve; (2) the presence of moderate or severe paravalvular leak at discharge; (3) the presence of a mean aortic valve gradient $20 \mathrm{~mm} \mathrm{Hg}$ or greater or peak velocity $3 \mathrm{~m} / \mathrm{s}$; and (4) intraoperative conversion to sutured valve implantation.

The combined safety end point at 30 days was defined as the absence of the following events: (1) all-cause mortality; (2) intraoperative conversion to sternotomy; (3) major stroke; (4) acute kidney injury stage 3 (including renal replacement therapy); (5) periprocedural myocardial infarction; (6) reoperation for bleeding; and (7) repeat procedure for valve-related dysfunction during the same recovery (surgical or interventional therapy). 
TABLE 1. Baseline characteristics by tertile

\begin{tabular}{|c|c|c|c|c|c|}
\hline Variable n $(\%)$ & Patients 1-100 & Patients 101-200 & Patients 201-300 & $P$ value & Total \\
\hline Age, mean (SD), y & $76 \pm 6$ & $76 \pm 7$ & $77 \pm 6$ & .532 & $76 \pm 6$ \\
\hline Age $>75 y$ & 63 & 63 & 76 & .077 & $202(67.3)$ \\
\hline Female gender & 69 & 60 & 61 & .532 & $191(63.6)$ \\
\hline Smoke & 22 & 20 & 11 & .094 & $53(17.7)$ \\
\hline Diabetes mellitus & 24 & 22 & 29 & .500 & $75(25)$ \\
\hline Hypertension & 84 & 73 & 70 & .001 & $217(72.3)$ \\
\hline Cerebrovascular disease & 9 & 3 & 7 & .082 & $19(6.3)$ \\
\hline Vascular disease & 14 & 21 & 14 & .303 & $49(16.3)$ \\
\hline COPD & 15 & 13 & 13 & .893 & $41(13.7)$ \\
\hline Redo & 2 & 2 & 2 & .99 & $6(2)$ \\
\hline History of AF & 3 & 3 & 7 & .276 & $13(4.3)$ \\
\hline PMK & 5 & 4 & 1 & .261 & $10(3.3)$ \\
\hline NYHA class III or IV & 33 & 16 & 19 & .009 & $68(22.7)$ \\
\hline Chronic kidney disease & 7 & 5 & 1 & .067 & $13(4.3)$ \\
\hline Preoperative dialysis & 2 & 2 & 0 & .195 & $4(1.3)$ \\
\hline $\mathrm{EF} \%$ & $58 \pm 8$ & $56 \pm 7$ & $57 \pm 6$ & .136 & $57 \pm 7$ \\
\hline $\mathrm{EF}<30 \%$ & 1 & 3 & 1 & .749 & $5(1.7)$ \\
\hline Logistic euroSCORE & $10 \pm 7$ & $8 \pm 6$ & $9 \pm 5$ & .212 & $9 \pm 6$ \\
\hline Urgent operation & 23 & 17 & 11 & .078 & $51(17)$ \\
\hline
\end{tabular}

$S D$, Standard deviation; $C O P D$, chronic obstructive pulmonary disease; $A F$, atrial fibrillation; $P M K$, pacemaker; $N Y H A$, New York Heart Association; $E F$, ejection fraction; euroSCORE, European System for Cardiac Operative Risk Evaluation.

Patients in whom more than 1 of these complications occurred were considered to have experienced only 1 primary outcome. CUSUM curves were generated prospectively using cumulative log-likelihood ratio charts, because this method has an immediate visual impact and can be constructed without the support of complex software. The statistical principles were adapted from the comprehensive tutorial by Rogers and colleagues. ${ }^{7}$ Basically, the CUSUM curve represents the consecutive performance of an individual or a team displayed as a line chart with the $\mathrm{X}$-axis representing the consecutive series of procedures and the Y-axis representing the CUSUM score. The resulting chart runs parallel to the $\mathrm{x}$ axis when the complication rate is as expected: turns upward when more complications than expected occur and turns downward when a favorably low complication rate is observed. For the purpose of this study, the acceptable failure rate was set at $5 \%$ for the device success end point and at $10 \%$ for the combined safety end point. Also, boundary lines are calculated to mark the borders for statistical significance. When the curve crosses one of the boundary lines, the graph is reset to 0 . The crossing of the upper boundary or the identification of a distinct cluster of failures prompted an internal audit, including data collection and analysis and collegial discussion of each adverse event.

Patient characteristics and outcomes were summarized using the mean and standard deviation or the median and the 25 th to 75 th percentile interquartile range for continuous variables, and frequency and percentage for categoric variables. Differences between tertiles were compared with the analysis of variance when appropriate for continuous variables and with the chi-square test when appropriate for categoric variables. Nonparametric methods were used for variables that were not normally distributed. Overall survival was evaluated using the Kaplan-Meier method, with an actuarial survival graph. All statistical analysis was performed with SPSS version 15.0 (SPSS Inc, Chicago, Ill).

\section{RESULTS}

During the 3-year study period, there has been a constant increase in the number of procedures. The median age of patients was $76 \pm 6$ years, with a median logistic European
System for Cardiac Operative Risk Evaluation I of $9.5 \pm 6.5$. A total of 191 patients were female $(63.6 \%)$, 75 patients $(25 \%)$ had diabetes, and 217 patients $(71 \%)$ had hypertension. Preprocedural assessment of the aortic valve revealed a mean ventriculo-aortic gradient of $79 \pm 24 \mathrm{~mm} \mathrm{Hg}$, with an aortic valve area of $0.8 \mathrm{~mm}^{2}$ and ejection fraction of $57 \% \pm 7 \%$. Patients were divided into tertiles, with 100 patients in each group, based on sequence number. Patients in tertiles 1 were more likely to be hypertensive $(P=.001)$ or severely symptomatic $(P=.009)$ compared with patients in tertiles 2 and 3 . No other significant differences were noted among the 3 groups (Table 1).

Operative data are reported in Table 2. A total of 36 patients $(12 \%), 89$ patients $(29.6 \%), 135$ patients $(45 \%)$, and 40 patients $(13 \%)$ received $21-\mathrm{mm}, 23-\mathrm{mm}, 25-\mathrm{mm}$, and 27-mm valve prostheses, respectively. The mean CPB time was $94 \pm 31$ minutes (range, 44-183 minutes), and crossclamping time was $60 \pm 21$ (range, 26-119 minutes). No differences were noted in terms of CPB and crossclamping time between tertiles $(P=.251)$. The Perceval $S$ sutureless valve was implanted in 298 patients $(99 \%)$. The device success end point was obtained in $96 \%, 97 \%$, and $96 \%$ of patients in the 3 tertiles $(P=.99)$. Technical adverse event details are reported in Table 1 . In regard to device success, the most frequent method of failure was the need to remove and reimplant the prosthesis for an intraoperative valve dysfunction ( 8 patients [2.6\%]), which accounted for $50 \%$ of all failures. In 6 patients, the valve was successfully reimplanted with only 2 patients who required a conversion to a sutured valve. Conversion to 
TABLE 2. Operative data by tertile

\begin{tabular}{|c|c|c|c|c|c|}
\hline Variable n $(\%)$ & Patients 1-100 & Patients 101-200 & Patients 201-300 & $P$ value & Total \\
\hline CPB time, $\min$ & $92 \pm 29$ & $98 \pm 41$ & $91 \pm 18$ & .251 & $94 \pm 31$ \\
\hline Crossclamping time, $\min$ & $58 \pm 20$ & $62 \pm 26$ & $58 \pm 12$ & .232 & $60 \pm 21$ \\
\hline Ascending aorta cannulation & 90 & 93 & 97 & .138 & $280(93.3)$ \\
\hline Femoral artery cannulation & 10 & 7 & 3 & .138 & $20(6.7)$ \\
\hline Device success end point & 97 & 96 & 97 & .725 & $287(95.7)$ \\
\hline Conversion to sternotomy & 0 & 2 & 1 & .364 & $3(1)$ \\
\hline Intraoperative valve dysfunction & 2 & 0 & 2 & .363 & $4(1.3)$ \\
\hline Conversion to sutured valve & 1 & 0 & 1 & .247 & $2(0.6)$ \\
\hline Removal/reimplantation & 3 & 3 & 2 & .407 & $6(2)$ \\
\hline Perceval S (Sorin Biomedica Cardio Srl, Saluggia, Italy) implantation & 99 & 100 & 99 & .786 & $298(99)$ \\
\hline
\end{tabular}

Interquartile range $=25$ th to 75 th percentile. $C P B$, Cardiopulmonary bypass.

sternotomy was necessary in 3 patients $(1 \%), 1$ for pulmonary artery perforation and 2 for bleeding. No significant differences in terms of method of failure for the device success end point were noted between tertiles.

The combined safety end point at 30 days was reached in $86 \%, 86 \%$, and $89 \%$ in the tertiles $(P=.767)$, with 39 patients who experienced at least 1 complication. The incidence of in-hospital mortality was $0,1 \%$, and $1 \%$ $(P=.604)$. The incidences of stroke $(3 \%, 0 \%, 3 \%$; $P=.216)$, new-onset dialysis $(7 \%, 5 \%, 1 \% ; P=.300)$, postoperative myocardial infarction $(1 \%, 2 \%, 0 \%$; $P=.247)$, and reoperation for bleeding $(4 \%, 5 \%, 2 \%$; $P=.517)$ or valve dysfunction $(1 \%, 0 \%, 2 \% ; P=.247)$ were similar between tertiles. No other significant differences were noted. Detailed postoperative data are shown in Table 3.

\section{Institutional Learning Curve for Device Success and Safety End Point}

Figures 1 and 2 depict the institutional CUSUM curves for the 2 end points. The analysis of the overall institutional curve for the device success end point did not reveal any significant learning effect, revealing that proficiency can be obtained and maintained after few procedures. Specifically, after a slight accumulation of failures at the beginning of the experience, the curve became consistently downward (ie, fewer technical failures than expected) and crossed the lower boundary line at operation 71. From operation 141, however, a small cluster of failure was evident. When analyzing the cluster, we found that 3 of the 4 failures consisted of misalignment of the prosthesis with the need to remove and reimplant the device. We found that the cluster was congruent with the introduction of the XL size of the Perceval S. Therefore, we speculate that the availability of a larger prosthesis was a confounding factor in patients with a borderline aortic annulus, and this led us to experience a second small learning curve. The curve continued to constantly decrease.

In regard to the combined safety end point at 30 days, the curve is characterized by an initial ascending portion likely related to the initial learning curve. An internal audit revealed that the majority of these failures were not related to technical or procedural issues, but to the high-risk profile and frailty of the treated patients. For these reasons, we developed an internal protocol for high-risk patients to be assigned to transcatheter aortic valve implantation (TAVI)

TABLE 3. Postoperative data by tertile

\begin{tabular}{|c|c|c|c|c|c|}
\hline Variables n $(\%)$ & Patients 1-100 & Patients 101-200 & Patients 201-300 & $P$ value & Total \\
\hline In-hospital mortality & 0 & 1 & 1 & .604 & $2(0.7)$ \\
\hline Stroke & 3 & 0 & 3 & .216 & $6(2.1)$ \\
\hline Transient & 2 & 0 & 2 & - & $4(1.4)$ \\
\hline Permanent & 1 & 0 & 1 & - & $2(0.7)$ \\
\hline Postoperative MI & 1 & 2 & 0 & .247 & $3(1)$ \\
\hline Renal dysfunction & 7 & 5 & 1 & .300 & $13(4.9)$ \\
\hline New-onset AV block & 3 & 4 & 3 & .923 & $10(3.3)$ \\
\hline Reoperation for bleeding & 4 & 5 & 2 & .517 & $11(3.7)$ \\
\hline Reoperation for valve dysfunction & 1 & 0 & 1 & .247 & $2(1)$ \\
\hline Clinical success end point & 86 & 86 & 89 & .767 & $261(87)$ \\
\hline Postoperative AF & 30 & 30 & 21 & .638 & 81 \\
\hline Assisted ventilation, $\mathrm{h}$, median & 6 (IQR 5-8) & 5 (IQR 4-8) & 5 (IQR 5-6) & .208 & 5 (IQR 4-8) \\
\hline ICU length of stay, $d$, median & $1(\mathrm{IQR} 1-1.75)$ & 1 (IQR 1-1.5) & 1 (IQR 1-1.5) & .168 & 1 (IQR 1-1.5) \\
\hline Postoperative length of stay, $\mathrm{d}$, median & 6 (IQR 6-7) & 6 (IQR 6-7) & 6 (IQR 6-8) & .907 & 6 (IQR 6-7) \\
\hline
\end{tabular}

$\mathrm{IRQ}=25$ th to 75 th percentile. $M I$, Myocardial infarction; $A V$, atrioventricular; $A F$, Atrial fibrillation; $I C U$, intensive care unit; $I Q R$, interquartile range. 


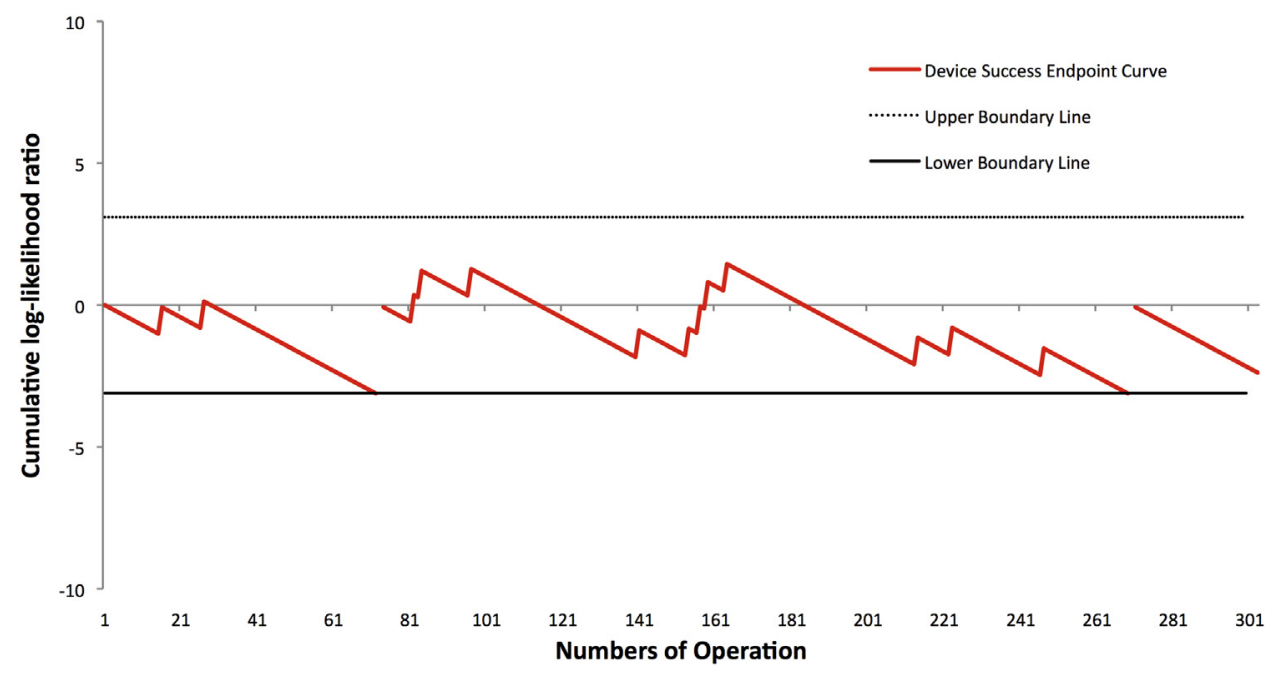

FIGURE 1. Departmental CUSUM curve for device success end point. The acceptable failure was set at 5\%.

or RAMT AVR with sutureless valves. The identification and correction of this problem led to a downward shift of the CUSUM curve that crossed the lower boundary line at operation 138. Another cluster of failure, with crossing of the upper boundary line, was identified between operation numbers 180 and 230. A careful review of these patients revealed that the majority of the failures were reoperation for bleeding. After the surgical staff become aware of the problem, the incidence of reoperation for bleeding started to decrease and the curve returned to run downward, crossing the lower boundary line at operation 290. It is important to note that these cluster of failures did not translate into a worse operative mortality.

\section{Individual Surgeons' Learning Curves for Device Success End Point}

The mean number of operations per surgeon was 50, with a range from 22 to 130 . There was a great variability among surgeons in their CUSUM failure curves (Figures 3 and 4).

Surgeon A (MG, who introduced the technique at our institution) has performed approximately half of the procedures in our institutional experience. He presented a curve that had a small accumulation of failures during the initial experience, and the curve started to move downward. No other cluster of failures were identified.

Surgeons B and C were directly trained by surgeon A. They presented a curve that reflected the typical learning

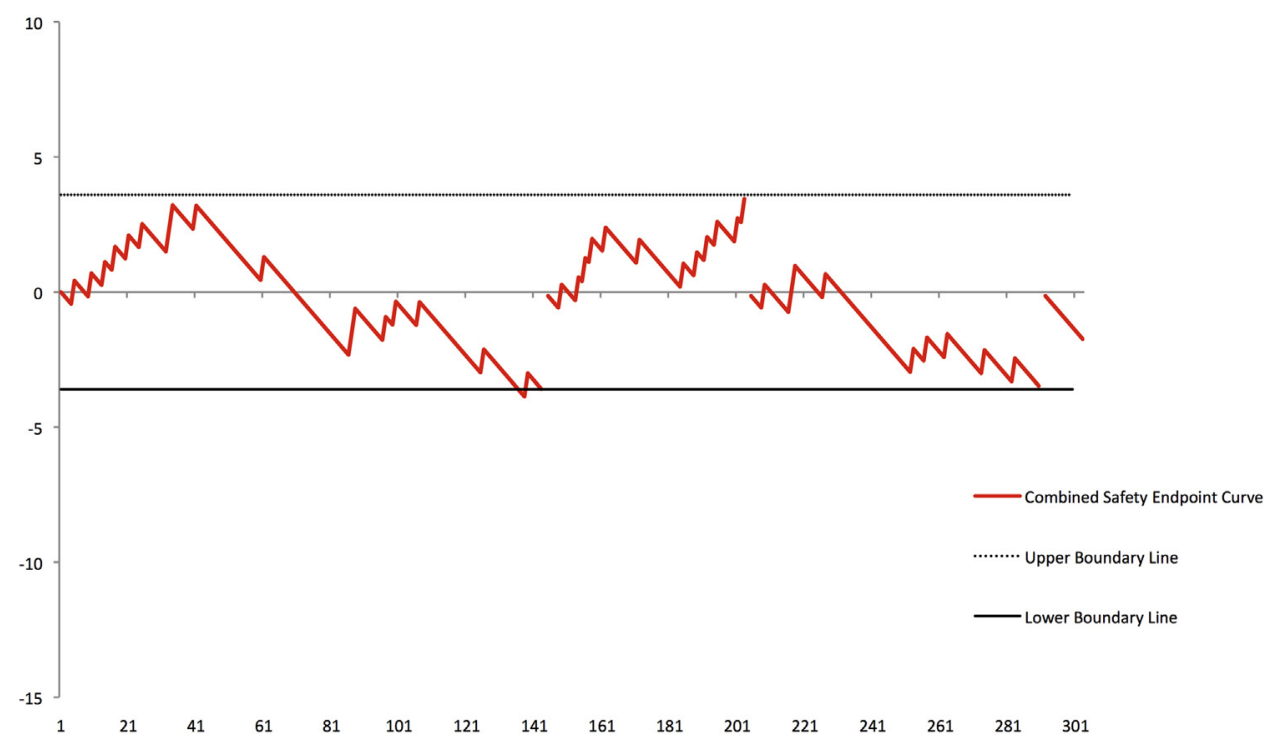

FIGURE 2. Departmental CUSUM curve for combined safety end point. The acceptable failure rate was set at $10 \%$. 


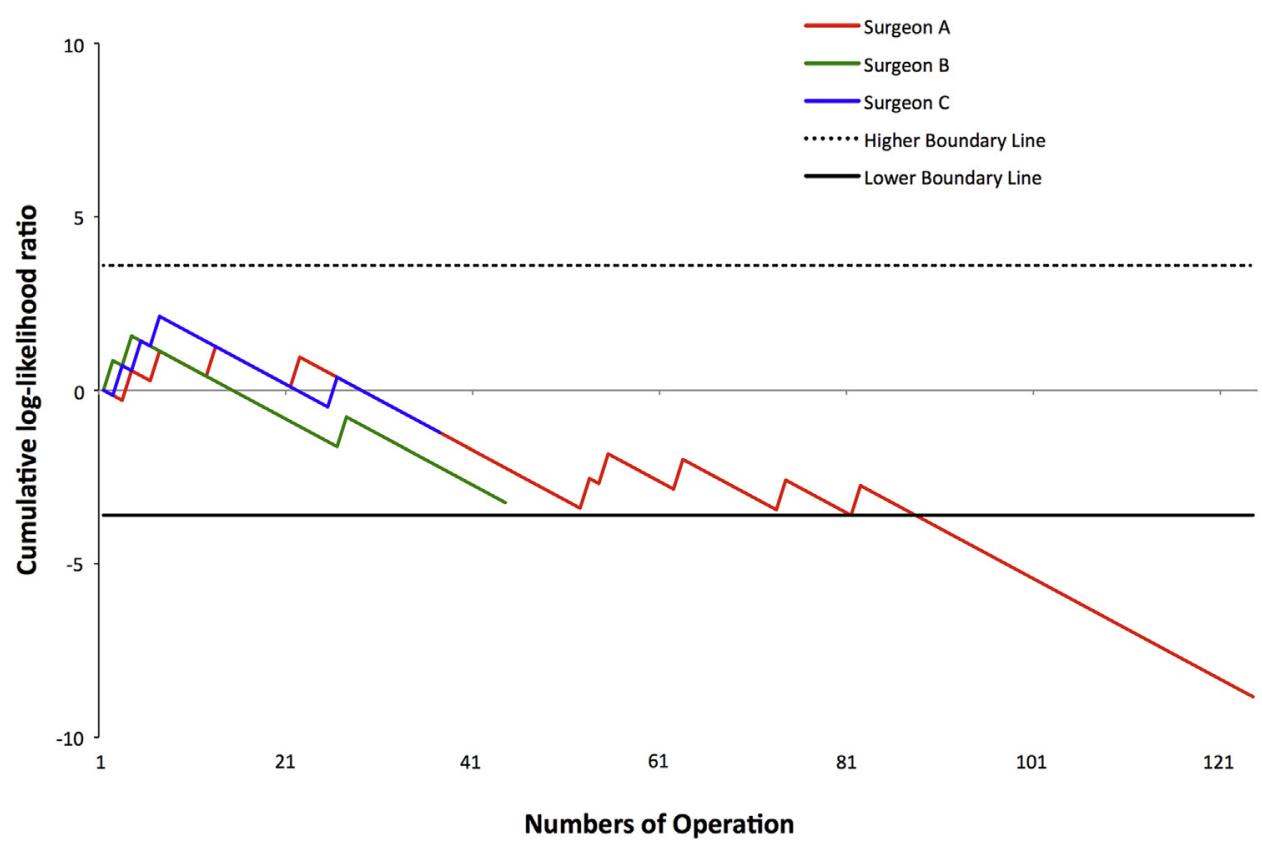

FIGURE 3. Individual CUSUM curves for device success end point for surgeons A, B, and C. The acceptable failure rate was set at $5 \%$.

curve process. The curves presented a steep slope at the beginning, followed by a small plateau, and then the curves started to move downward, reflecting better than expected results. It is of interest that surgeons $\mathrm{D}, \mathrm{E}$, and F, who were introduced to the program late, were performing well, and their curves did not show any learning curve effects.

\section{Follow-up}

For all patients, mandatory transthoracic echocardiography was performed before discharge. Mean transprosthetic pressure gradient at discharge was $13 \mathrm{~mm} \mathrm{Hg}$, and the peak pressure gradient was $22 \mathrm{~mm} \mathrm{Hg}$. At discharge, 2 patients presented a moderate periprosthetic leak. During the follow-up period, echocardiography control was performed 3,6 , and 12 months after the procedure. No valve migration or valve thrombosis was observed during follow-up. With regard to paravalvular leakage, there was no deterioration or new onset of regurgitation during the follow-up. Of 2 patients with moderate paravalvular leakage at discharge, 1 patient reached 18 months of follow-up (regurgitation

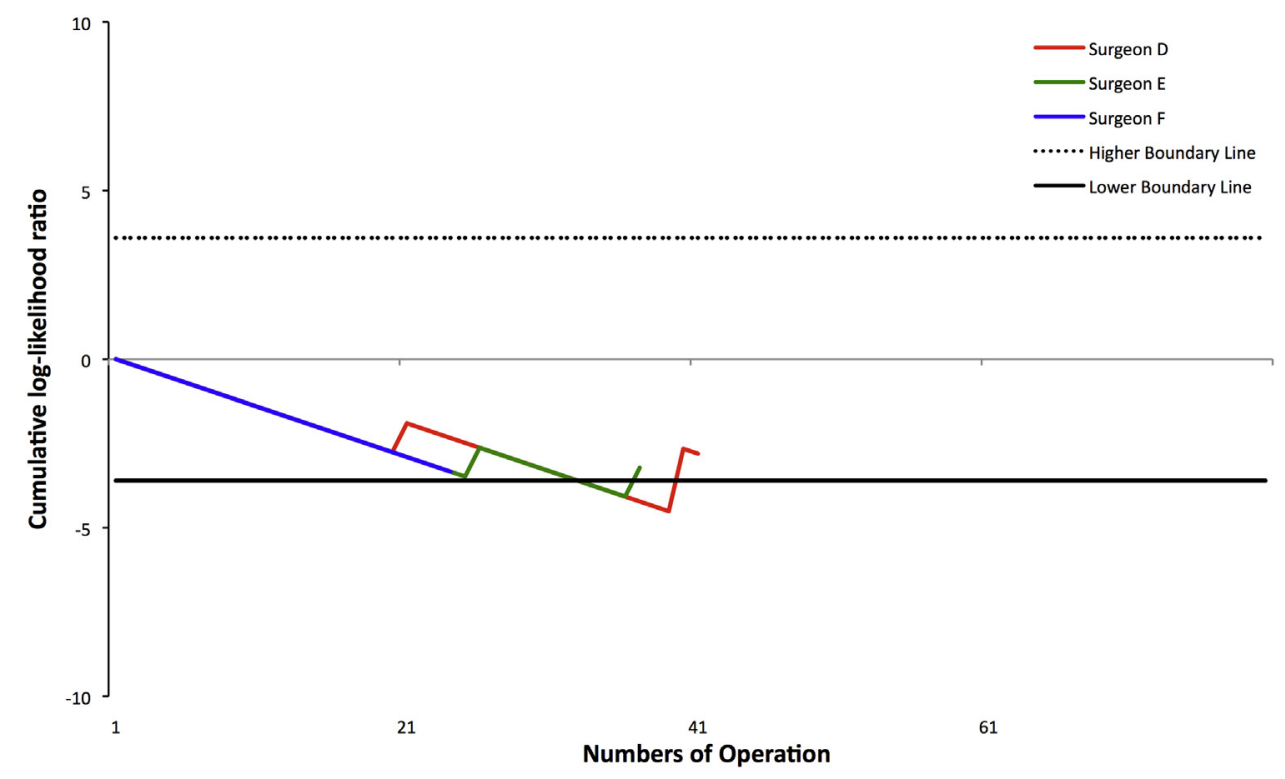

FIGURE 4. Individual CUSUM curves for device success end point for surgeons D, E, and F. The acceptable failure rate was set at $5 \%$. 


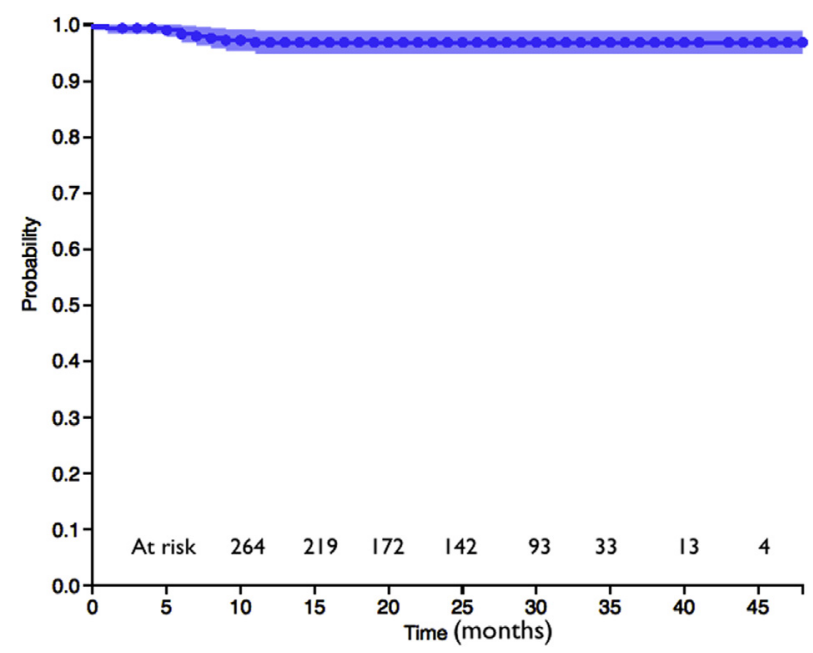

FIGURE 5. Overall survival curve by Kaplan-Meier test for general cohort.

degree remained stable in all cases). Reoperation was necessary in 1 patient for active endocarditis. Median follow-up was $22 \pm 10$ months. There were 9 late deaths during the study period. Long-term survival at 1 and 3 years was $99 \% \pm 0.1 \%$ and $82 \% \pm 0.6 \%$, respectively (Figure 5).

\section{DISCUSSION}

Since Benetti and colleagues ${ }^{11}$ first described the RAMT approach in 1997, some publications have demonstrated that the short-term results of this technique are at least as good as, if not better than, conventional AVR performed via the standard median sternotomy. ${ }^{1-3,12-14}$ However, despite these potential benefits, many surgeons are still reluctant to perform AVR through a small right thoracotomy. The reasons for this surgical reluctance are multifactorial. They include the lack of established training programs, the perception that success with the technique is limited to more proficient surgeons, and a fear of deleterious patient outcomes, especially during the learning curve. Moreover, detractors of this approach claim that the major drawback of the procedure is represented by a significant increase in CPB and crossclamp time due to technical difficulties in implanting a sutured aortic prosthesis through a narrow working field with limited visibility. The recently introduced Perceval S sutureless aortic valve bioprosthesis represents a new valve design that aims to maintain the native anatomy of the aortic root, aortic sinuses, and sinotubular junction. Similar to other sutureless bioprosthetic valves, the Perceval S is a self-expanding valve (only short exposition under a balloon inflation may be needed) and has the potential to shorten the implantation time, thus facilitating minimally invasive AVR, especially in a subset of patients who may benefit from reduction of crossclamping and extracorporeal circulation times. ${ }^{4-6}$ Since the beginning of our experience, we have found the Perceval $S$ valve particularly effective for the RAMT procedure. ${ }^{8}$ A limited working room issue is easily handled with this sutureless prosthesis. Because of its collapsing delivery system, this prosthesis allows good intraoperative exposure of the aortic root during the procedure, even in patients with suboptimal anatomic situations. Because of this, a small right thoracotomy has become the preferred approach for AVR at the G. Pasquinucci Heart Hospital, and since then, the number of these procedures has increased significantly. The number of surgeons introduced to this technique has increased significantly, and all the surgical staff routinely perform AVR through a RAMT. The consistency in patient selection, a standardized surgical technique, and perioperative management over the study period allowed us a unique opportunity to assess the Perceval S RAMT learning curve at the G. Pasquinucci Heart Hospital.

In previous studies, we have used CUSUM to monitor the performance of the surgeons introduced to minimally invasive cardiac surgery techniques with excellent results $^{15,16}$; therefore, it was natural to use this methodology to assess our institutional and individual learning curve associated with this new AVR procedure. The basic principle of the CUSUM curve is reward or punishment with each consecutive attempt, according to the inherent risk of the procedure. It can be repeated as often as desired, even after each operation, providing an almost real-time monitoring of surgical performance.

The calculation of learning curves for the entire group of surgeons supplied a general impression of the learning process of this operative technique. Indeed, when observing our results, it is evident that both the tertile analysis and the institutional CUSUM curves did not show any significant learning curve effects. In addition, it is particularly clear that proficiency in the technique can be obtained from the beginning of the experience by the majority of the surgeons. Our study failed to identify typical learning curve patterns with regard to cardiopulmonary and aortic crossclamp times. However, compared with our previous results with conventional sutured valve prosthesis implantation through RAMT, ${ }^{17}$ the sutureless prosthesis was associated with significantly reduced CPB and crossclamping times.

In regard to the device success end point, a technical success was obtained in $98 \%$ of the patients, and we did not observe any significant variation of this rate during the study period. It is of particular interest to underline how these data are confirmed by the fact that the Perceval $\mathrm{S}$ was implanted in $99 \%$ of the patients, with only 2 patients who required a conversion to a sutured prosthesis. Moreover, these 2 conversions were performed by a single surgeon, with the remaining surgeons experiencing $100 \%$ successful implantations. Our analysis revealed that in 
$2 \%$ of patients, there was the need to remove, recollapse, and reimplant the Perceval $S$ valve because of incorrect alignment. We hypothesized that prosthesis malposition would have been the method of failure with the higher learning curve and that proficiency in correct valve deployment would improve with case numbers. Surprisingly, we failed to identify any learning effects on these technical aspects as evidenced by the tertile analysis. We also ran a separate CUSUM on this particular failure, but no learning curve effect was evident. Since the beginning of our experience, we recognized that the reasons for prosthesis malposition are multifactorial, but the majority of cases were related to incorrect sizing or incorrect visualization of the nadir with subsequent malpositioning of the guiding sutures. For these reasons, we have developed some tips to standardize the implantation technique. First, decalcification of the annulus should be extensive, leaving no annular calcification that could impede complete sealing of the stent of the Perceval $S$ valve. Second, the sizing of the valve must be meticulous. The sizer should slightly pass through the aortic annulus with small resistance, and when inserted, it should allow the insertion of the tips of a DeBakey forceps at the level of the 3 commissures. In case of borderline sizing, the biggest size of the prosthesis must be implanted. Third, in an effort to facilitate guide sutures passing, we always start passing sutures through the left sinus, then move to the noncoronary sinus, and finally the right coronary sinus. A gentle traction on the 2 guide sutures placed on the left and noncoronary sinus usually allows a confortable and complete visualization of the right coronary sinus, which is the most difficult part to visualize in a right thoracotomy procedure. Fourth, once the valve is released, we always check it for a perfect positioning of the prosthesis during deployment, which should be symmetrically seated in the aortic annulus, perfectly coapt with the aortic annulus and completely covering it so no part of the native aortic annulus is exposed and visible under the valve prosthesis. An incorrect alignment of the valve usually is revealed by a distortion of the shape of the leaflets, with 1 of them that is not coapt with the other 2. Different from other sutureless prostheses, in case of incorrect deployment, the valve can be removed and reimplanted easily. The reuse of the same prosthesis offers the advantages of a shorter crossclamping time and a substantial reduction in the procedure-related costs per patient. In our series, the incidence of paravalvular leakage was $1.3 \%$ and in line with previous reports on the Perceval $\mathrm{S}$ valve. ${ }^{4-6,18}$ Our current policy is to immediately resolve any doubt about prosthesis distortion or misalignment in the operating room and to not tolerate even mild residual regurgitation.

Another important aspect that can be observed from the device success end point curves of each surgeon is the presence of a small learning curve for surgeons A, B, and
C but not for the other surgeons. Surgeon A was the first to systematically apply the Perceval S RAMT, and he directly trained surgeons B and C. On the other hand, surgeons $\mathrm{D}, \mathrm{E}$, and $\mathrm{F}$ were introduced to Perceval $\mathrm{S}$ implantation later on, when the overall institutional experience was more consistent. Therefore, we speculate that their learning curve was mitigated by the availability of several safety mechanisms and parachutes, including higher institutional experience, improved standards for patients' selection and assessment, and in general "transmitted learning" from surgeons with greater experience. Training inexperienced surgeons to perform new surgical techniques can affect department results and performance. For this reason, it is mandatory that surgical training is structured and closely monitored. In an effort to minimize the learning curve during the study period, we have developed a training strategy that consists of 3 steps: (1) Each surgeon who is introduced to RAMT is first assisted by experienced surgeons during preparation of patients for RAMT in an effort to learn technical tips (correct patient selection, cardiopulmonary bypass institution and aortic valve exposure, and annulus decalcification). (2) At the same time, the surgeon becomes familiar with the sutureless valve technology performing some implants of the Perceval $S$ in those cases performed via a full sternotomy. (3) Finally, the trainee starts to perform unsupervised procedures. Even the use of video assistance represents an important tool for surgeons introduced to the Perceval S RAMT. The camera allows for interactive valve checking, and the trainees, in case of doubts, have the chance to actively discuss matters with more experienced surgeons. In our series, a conversion to sternotomy was necessary in 3 patients $(1 \%)$. In 1 patient, we observed a pulmonary artery injury due to aortic clamping. In the other 2 patients, the reason was bleeding from the aortic root. In these 2 patients, we removed the prosthesis, and after repairing the root, we implanted a sutured valve. Although other series have reported an increased morbidity and mortality after conversion to sternotomy, ${ }^{19}$ these 3 patients had an uneventful postoperative course.

When observing the CUSUM curve for early 30-day outcome, a cluster of clinical failures were evident at the beginning of the experience. This cluster of failure prompted an internal audit. Careful analysis of all the adverse events revealed that failures were not related to technical or procedural issues, but to the high-risk profile and frailty of the treated patients. The identification of this problem led to the development of an institutional protocol for the evaluation of "high-risk patients." From that time, every patient considered to be at high risk, independently of the value of the logistic European System for Cardiac Operative Risk Evaluation, is evaluated by a multidisciplinary Heart Team, which has the aim to identify 
the most effective method of treatment, including standard AVR, RAMT, or TAVI. After the implementation of this patient-oriented multidisciplinary assessment, we have observed a downward shift of the CUSUM curve, reflecting a clear improvement of the performance. Although TAVI has shown excellent results when compared with standard therapy, controversies exist when compared with a surgical population. Several studies have focused on the role of TAVI or sutureless valve replacement in high-risk patients considered to be in the gray zone between TAVI and surgery. ${ }^{20}$ In a propensity-matched analysis, Santarpino and colleagues ${ }^{21}$ showed better outcomes in patients undergoing ministernotomy and sutureless AVR than in patients undergoing TAVI. Our group reported similar results when outcomes were compared between the RAMT approach and the sutureless and TAVI procedures. ${ }^{22}$ A recent study published in the Journal by the Italian Transcatheter Balloon-Expandable Registry and the Sutureless Aortic Valve Implantation Research Groups ${ }^{23}$ analyzed a total of 2177 patients: $1885(86.6 \%)$ treated with TAVI and $292(13.4 \%)$ treated with sutureless AVR. The authors reported a better device success and a lower incidence of any paravalvular leakage with sutureless technology compared with TAVI. Therefore, in light of the good hemodynamic performance of sutureless valves and the low rate of postoperative complications and paravalvular leakages, we believe that the association of MIAVR and sutureless valves may be a valid alternative to the new growing TAVI technology in high-risk "operable patients."

\section{Study Limitations}

The study has several limitations that are important to consider when interpreting the results. This study is based on the analysis of our institutional, observational, prospectively collected database, and thus it reflects single-center experience only. This may limit its generalizability to other centers. Although the study was designed to assess our learning curve, it should be noted that at the beginning of the study, surgeon A had a huge experience with RAMT for sutured AVR, and this may have hampered his results. One important variable was not documented in the database, namely, a shift from a less experienced to a more experienced surgeon designation as the main operator. We do not believe that this occurred to a significant extent; however, during the early stages of training, a more experienced surgeon may have intervened in an unplanned manner to help the less experienced surgeon. In addition, the way in which control charts are set up needs to be considered carefully. In our study, for example, we have used unadjusted CUSUM curves with an acceptable failure rate of $5 \%$ for device success end point and $10 \%$ for the combined safety end point. After a careful literature review, we decided to use these acceptable failure rate values because many publications on large consecutive minimally invasive AVR series ${ }^{24,25}$ revealed major complication rates of $10 \%$ to $15 \%$, and our target was directed toward the lower end of this range. Also, the fact that we did not use adjusted curves may be seen as a limit. However, a risk-adjusted analysis can be only as good as the underlying risk prediction model, and actually no risk model exist for sutureless AVR. Nevertheless, we have drawn a combined safety end point curve adjusted for the Society of Thoracic Surgeons score, and the results were similar to the unadjusted combined safety end point curve.

\section{CONCLUSIONS}

New cardiac surgical procedures demand a close outcome analysis, especially during the initial phase of application, and the CUSUM technique, which alerts the surgical team to suboptimal results, represents the ideal statistical tool. Indeed, this method is sufficiently sensitive and simple. Our analysis revealed that RAMT for Perceval S implantation can be performed safely, as well as during the initial experience without any learning curve effects.

\section{Conflict of Interest Statement}

M.G. and M.S. have a commercial/financial relationship with the Sorin Group. All other authors have nothing to disclose with regard to commercial support.

\section{References}

1. Cohn LH, Adams DH, Couper GS, Bichell DP, Rosborough DM, Sears SP, et al. Minimally invasive cardiac valve surgery improves patient satisfaction while reducing costs of cardiac valve replacement and repair. Ann Surg. 1997;226: 421-8.

2. Tabata M, Umakanthan R, Cohn LH, Bolman RM III, Shekar PS, Chen FY, et al. Early and late outcomes of 1000 minimally invasive aortic valve operations. Eur J Cardiothorac Surg. 2008;33:537-41

3. Glauber M, Miceli A, Bevilacqua S, Farneti PA. Minimally invasive aortic valve replacement via right anterior minithoracotomy: early outcomes and mid term follow-up. J Thorac Cardiovasc Surg. 2011;142:1557-9.

4. Shrestha M, Khaladj N, Bara C, Hoeffler K, Hagl C, Haverich A. A staged approach towards interventional aortic valve implantation with a sutureless valve: initial human implants. Thorac Cardiovasc Surg. 2008;56:398-400.

5. Shrestha M, Folliguet T, Meuris B, Dibie A, Bara C, Herregods MC, et al. Sutureless Perceval S aortic valve replacement: a multicenter, prospective pilot trial. J Heart Valve Dis. 2009;18:698-702.

6. Folliguet TA, Laborde F, Zannis K, Ghorayeb G, Haverich A, Shrestha M. Sutureless Perceval aortic valve replacement: results of two European centers. Ann Thorac Surg. 2012;93:1483-8.

7. Rogers CA, Reeves BC, Caputo M, Ganesh JS, Bonser RS, Angelini GD. Control chart methods for monitoring cardiac surgical performance and their interpretation. J Thorac Cardiovasc Surg. 2004;128:811-9.

8. Gilmanov D, Miceli A, Bevilacqua S, Farneti P, Solinas M, Ferrarini M, et al. Sutureless implantation of the Perceval $\mathrm{S}$ aortic valve prosthesis through right anterior minithoracotomy. Ann Thorac Surg. 2013;96:2101-8.

9. Caputo M, Reeves B, Rogers C, Ascione R, Angelini G. Monitoring the performance of residents during training in off-pump coronary surgery. $J$ Thorac Cardiovasc Surg. 2004;128:907-15.

10. Holzhey DM, Jacobs S, Walther T, Mochalski M, Mohr FW, Falk V. Cumulative sum failure analysis for eight surgeons performing minimally invasive direct coronary artery bypass. J Thorac Cardiovasc Surg. 2007;134:663-9.

11. Benetti F, Rizzardi JL, Concetti C, Bergese M, Zappetti A. Minimally aortic valve surgery avoiding sternotomy. Eur J Cardiothorac Surg. 1999;16:S84-5. 
12. Brinkman WT, Hoffman W, Dewey TM, Culica D, Prince SL, Herbert MA, et al. Aortic valve replacement surgery: comparison of outcomes in matched sternotomy and PORT ACCESS groups. Ann Thorac Surg. 2010;90:131-5.

13. Ruttmann E, Gilhofer TS, Ulmer H, Chevtchik O, Kocher A, Schistek R, et al. Propensity score-matched analysis of aortic valve replacement by mini-thoracotomy. J Heart Valve Dis. 2010;19:606-14.

14. Gilmanov D, Bevilacqua S, Murzi M, Cerillo AG, Gasbarri T, Kallushi E, et al. Minimally invasive and conventional aortic valve replacement: a propensity score analysis. Ann Thorac Surg. 2013;96:837-43.

15. Murzi M, Cerillo AG, Bevilacqua S, Gilmanov D, Farneti P, Glauber M Traversing the learning curve in minimally invasive heart valve surgery: a cumulative analysis of an individual surgeon's experience with a right minithoracotomy approach for aortic valve replacement. Eur J Cardiothorac Surg. 2012;41:1242-6.

16. Murzi M, Cerillo AG, Bevilacqua S, Gasbarri T, Kallushi E, Farneti P, et al. Enhancing departmental quality control in minimally invasive mitral valve surgery: a single-institution experience. Eur J Cardiothorac Surg. 2012;42:500-6.

17. Gilmanov D, Miceli A, Ferrarini M, Farneti P, Murzi M, Solinas M, et al. Aortic valve replacement through right anterior minithoracotomy: can sutureless technology improve clinical outcomes? Ann Thorac Surg. 2014;98:1585-92.

18. Santarpino G, Pfeiffer S, Schmidt J, Concistrè G, Fischlein T. Sutureless aortic valve replacement: first-year single-center experience. Ann Thorac Surg. 2012; 94:504-9.

19. Vollroth M, Seeburger J, Garbade J, Pfannmueller B, Holzhey D, Misfeld M, et al. Minimally invasive mitral valve surgery is a very safe procedure with very low rates of conversion to full sternotomy. Eur J Cardiothorac Surg. 2012;42:e13-5.
20. D’Onofrio A, Messina A, Lorusso R, Alfieri OR, Fusari M, Rubino P, et al Sutureless aortic valve replacement as an alternative treatment for patients belonging to the "gray zone" between transcatheter aortic valve implantation and conventional surgery: a propensity-matched, multicenter analysis. J Thorac Cardiovasc Surg. 2012;144:1010-6.

21. Santarpino G, Pfeiffer S, Fischlein T. Sutureless aortic valve replacement to prevent patient-prosthesis mismatch in the era of valve-in-valve implantation. J Thorac Cardiovasc Surg. 2012;144:279-80.

22. Miceli A, Gilmanov D, Murzi M, Marchi F, Ferrarini M, Cerillo AG, et al. Minimally invasive aortic valve replacement with a sutureless valve through a right anterior mini-thoracotomy versus transcatheter aortic valve implantation in high-risk patients. Eur J Cardiothorac Surg. 2016;49: 960-5.

23. D'Onofrio A, Salizzoni S, Rubino AS, Besola L, Filippini C, Alfieri O, et al. The rise of new technologies for aortic valve stenosis: a comparison of sutureless and transcatheter aortic valve implantation. J Thorac Cardiovasc Surg. 2016;152: 99-109.e2.

24. Brown ML, McKellar SH, Sundt TM, Schaff HV. Ministernotomy versus conventional sternotomy for aortic valve replacement: a systematic review and meta-analysis. J Thorac Cardiovascular Surg. 2009;137:670-9.

25. Murtuza B, Pepper JR, Satnbridge RD, Jone C, Rao C, Darzi A, et al. Minimal access aortic valve replacement: is it worth it? Ann Thorac Surg. 2008;85 1121-31.

Key Words: aortic valve replacement, performance monitoring, sutureless aortic valve

Readers who found these articles interesting may also like to read the following papers found in recent and future issues of our sister publications, Seminars in Thoracic and Cardiovascular Surgery and Operative Techniques in Thoracic and Cardiovascular Surgery!

\section{Acquired: Aortic Disease}

Original Submission: Outcomes of Open Surgical Repair for Type B Dissecting Aortic Aneurysm with Alternative Methods in the Endovascular Stent Era. Mitsumasa Hata. Semin Thorac Cardiovasc Surg 2015; Summer; 27(2):106-112.

Editorial Commentary: It is Difficult to Compare Apples and Oranges: Acute and Chronic Type B Aortic Dissections, Complicated and Uncomplicated, are Different and Should be Treated as Such. Ourania Preventza. Semin Thorac Cardiovasc Surg 2015; Summer 27(2):113-114.

News and Views: Treatment of Thoracic Aortic Aneurysm: Role of Earlier Intervention. Bulat A. Ziganshin. Semin Thorac Cardiovasc Surg 2015; Summer; 27(2);135-143.

Aortic root enlargement during aortic valve replacement: Nicks and Manouguian techniques. Kendra J Grub. Oper Tech Thorac Cardiovasc Surg 2015; Autumn; 20(3):206-218.

The Konno-Rastan procedure for anterior aortic annular enlargement. Mark E. Roeser. Oper Tech Thorac Cardiovasc Surg 2015: Autumn; 20(3):219-233. 


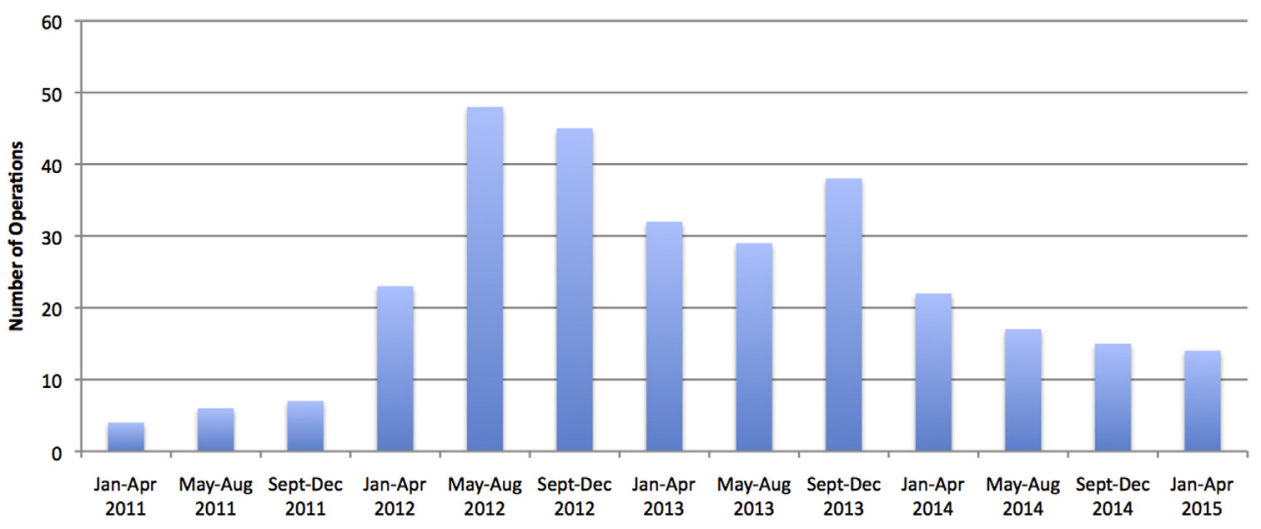

FIGURE E1. Number of operations reported on a 4-monthly basis. 